\title{
Haemophilus parasuis Subunit Vaccines Based on Native Proteins with Affinity to Porcine Transferrin Prevent the Expression of Proinflammatory Chemokines and Cytokines in Pigs
}

\author{
R. Frandoloso, ${ }^{1,2}$ S. Martínez-Martínez, ${ }^{1}$ E. F. Rodríguez-Ferri, ${ }^{1}$ S. Yubero, ${ }^{1}$ \\ D. Rodríguez-Lázaro, ${ }^{3}$ M. Hernández, ${ }^{3}$ and C. B. Gutiérrez-Martín ${ }^{1}$ \\ ${ }^{1}$ Unidad de Microbiología e Inmunología, Departamento de Sanidad Animal, Facultad de Veterinaria, Universidad de León, \\ 24007 León, Spain \\ ${ }^{2}$ Laboratório de Imunologia e Doenças Infecto-Contagiosas, Faculdade de Agronomia e Medicina Veterinária, \\ Universidade de Passo Fundo, 99052-900 Passo Fundo, RS, Brazil \\ ${ }^{3}$ Instituto Tecnológico Agrario de Castilla y León (ITACyL), 47071 Valladolid, Spain
}

Correspondence should be addressed to C. B. Gutiérrez-Martín; cbgutm@unileon.es

Received 3 July 2013; Revised 22 August 2013; Accepted 27 September 2013

Academic Editor: Roy Ambli Dalmo

Copyright (C) 2013 R. Frandoloso et al. This is an open access article distributed under the Creative Commons Attribution License, which permits unrestricted use, distribution, and reproduction in any medium, provided the original work is properly cited.

\begin{abstract}
The expression of chemokines (CCL- 2 and CXCL- 8 ) and cytokines (IL- $1 \alpha$, IL- $1 \beta$, IL-6, TNF- $\alpha$, and IL-10) was evaluated by RTqPCR in colostrum-deprived pigs vaccinated and challenged with Haemophilus parasuis serovar 5. Two vaccines containing native proteins with affinity to porcine transferrin (NPAPTim and NPAPTit) were tested, along with two control groups: one inoculated with PBS instead of antigen (challenge group (CHG)), and another one nonimmunized and noninfected (blank group). The use of NPAPTim and NPAPTit resulted in complete protection against $H$. parasuis (no clinical signs and/or lesions), and both vaccines were capable of avoiding the expression of the proinflammatory molecules to levels similar to physiological values in blank group. However, overexpression of all proinflammatory molecules was observed in CHG group, mainly in the target infection tissues (brain, lungs, and spleen). High expression of CCL-2, CXCL-8, IL- $1 \alpha$, IL-1 $\beta$, and IL- 6 can be considered one of the characteristics of $H$. parasuis infection by serovar 5 .
\end{abstract}

\section{Introduction}

During infection Haemophilus parasuis needs to establish replicative niches in a host that possesses a robust innate immune system, which is an evolutionary ancient form of host defense in multicellular organisms [1]. When $H$. parasuis succeeds in overcoming this response via depletion of specific cell populations [2], Glässer's disease, a severe systemic disorder, develops in pigs.

Proinflammatory cytokines, such asinterferon- $\alpha$ (IFN- $\alpha$ ), tumour necrosis factor- $\alpha$ (TNF- $\alpha$ ), interleukin-1 (IL-1), IL6 , and IL- 8 , are produced during the acute stage of bacterial infection [3-5] and play a pivotal role in the modulation and orchestration of the innate immune response. Each of these molecules has a number of different local and systemic effects, such as macrophage activation [6], increase in adhesion molecules on the vascular endothelium $[7,8]$, induction of acute phase proteins [9], and neutrophil chemotaxis and activation [10]. Some bacterial molecules as LPS can induce the production of proinflammatory cytokines, which results in fever, hypotension, inadequate tissue perfusion, metabolic acidosis, septic shock, and organ failure [11]. In order to regulate the severity of the inflammatory response, immune system has some cytokines, such as IL-10, which are capable of inhibiting a large amount of cytokines and chemokines secreted by macrophages and activated monocytes $[12,13]$. 
Little is known about the interaction between $H$. parasuis and cytokine expression in pigs, which hinders the understanding of Glässer's disease pathogenesis and the development of effective vaccines. We evaluated in this study the capability of a subunit vaccine to inhibit the transcription of a set of chemokines and cytokines directly related to inflammation, in systemic and target infection organs. Colostrum-deprived pigs [14] were used as animal model in order to avoid the endemic colonization by $H$. parasuis in the upper respiratory tract of suckling piglets that have contact with their sows.

\section{Materials and Methods}

2.1. Vaccines, Experimental Groups and Immunization. Two vaccines based on native proteins with affinity to porcine transferrin (NPAPTim and NPAPTit) [15] were compared. NPAPTim contained $400 \mu \mathrm{g}$ of NPAPT antigen adjuvanted with Montanide IMS 2215 VG PR (Seppic Inc., Paris, France) in a $1: 4$ ratio. NPAPTit contained the same antigen but potentiated with neuraminidase from Clostridium perfringens (type $\mathrm{VI}$ ) at a concentration of $100 \mathrm{mU} / \mathrm{mL}$. Twenty colostrumdeprived pigs were randomly assigned to four experimental groups. The NPAPTim group $(n=6)$ received $2 \mathrm{~mL}$ of NPAPTim vaccine by intramuscular injection at 28 and 49 days of age, while the NPAPTit group $(n=6)$ received the same volume of NPAPTit vaccine by intratracheal injection at the same days. The challenge control (CHG) group $(n=$ 4) received $2 \mathrm{~mL}$ of PBS intramuscularly at the same days. These three groups were challenged intratracheally at 63 days with a lethal dose $\left(3 \times 10^{8} \mathrm{CFU}\right)$ of $H$. parasuis Nagasaki strain (serovar 5 ). The fourth group $(n=4)$ comprised pigs that were maintained as nonimmunized, noninfected blank group. All experiments were conducted in accordance to the guidelines of the University of León Ethical Committee. Surviving pigs were humanely euthanized at 78 days. More details of this schedule have been already reported [15].

2.2. Sample Collection and RNA Extraction. This description is based on the MIQE guidelines [16]. After necropsy, small pieces $(\leq 0.5 \mathrm{~cm})$ from brain, lungs, spleen, and mediastinal, tracheobronchial, and mandibular nodes from each pig were collected aseptically and maintained in RNA later solution (Ambion-Applied Biosystems, Life Technologies, USA) overnight at $4^{\circ} \mathrm{C}$. After centrifugation, the supernatant was discarded, and the samples were stored at $-80^{\circ} \mathrm{C}$. Total cellular RNA was purified from $30 \mathrm{mg}$ of tissue of each sample, using the RNAspin Mini RNA Isolation Kit (GE Healthcare, Spain). Samples were maintained at $-80^{\circ} \mathrm{C}$ in $40 \mu \mathrm{L}$ of RNase free water. Immediately before performing the cDNA synthesis, the concentration and quality (integrity) of the total RNA were checked by a capillary electrophoresis system, using the Agilent 2100 Bioanalyzer and the RNA 6000 Pico Chip Kit. All RNA obtained had a RNA integrity number (RIN) higher than 7 (scale 1 to 10).

2.3. cDNA Synthesis. The first-strand cDNA synthesis was carried out by reverse transcription (RT) from total RNA using the SuperScript III First-Strand Synthesis SuperMix (Invitrogen Life Technologies, USA). Briefly, $2 \mu \mathrm{g}$ of total RNA was primed with $1 \mu \mathrm{L}$ of random hexamers $(50 \mathrm{ng} / \mu \mathrm{L})$ and $1 \mu \mathrm{L}$ of annealing buffer and was completed until $8 \mu \mathrm{L}$ with RNase free water. It was incubated at $65^{\circ} \mathrm{C}$ for $5 \mathrm{~min}$ and then immediately placed on ice for $1 \mathrm{~min}$. Afterwards, $10 \mu \mathrm{L}$ of $2 \times$ First-Strand Reaction Mix and $2 \mu \mathrm{L}$ of SuperScript III/RNaseOUT Enzyme Mix were added to the tube on ice and incubated at $25^{\circ} \mathrm{C}$ for $10 \mathrm{~min}$, at $50^{\circ} \mathrm{C}$ for $50 \mathrm{~min}$ and at $85^{\circ} \mathrm{C}$ for $5 \mathrm{~min}$, to stop the reaction. The resulting $\mathrm{cDNA}$ was diluted 10 times and stored at $-80^{\circ} \mathrm{C}$ until use.

2.4. Primers and Probes Design. The set of primers and hydrolysis probes used to determine the expression of chemokines (CCL2 and CXCL-8), cytokines (IL- $1 \alpha$, IL-1 $\beta$, IL-6, TNF- $\alpha$, and IL-10), and reference genes (GAPDH, $\beta$-actin, cyclophilin) were designed for this study or obtained from previous reports (Table 1). Hydrolysis probes were labeled with 6-carboxy-fluorescein (FAM) at the $5^{\prime}$ end and the Black Hole Quencher $\left(\mathrm{BHQ}_{1}\right.$ or $\left.\mathrm{BHQ}_{2}\right)$ at the $3^{\prime}$ end.

2.5. Development of a PCR Internal Control. The cDNA obtained from tracheobronchial nodes of CHG group was amplified using the primers described in Table 1, including a final step of $72^{\circ} \mathrm{C}$ for $30 \mathrm{~min}$. The PCR-specific product from every gene was cloned into the pGEM-T-Easy vector (Promega, Spain) according to the manufacturer's instructions.

2.6. Quantitative Real-Time PCR ( $q P C R$ ) Analysis. Quantitative real-time PCRs were carried out in 96-well plates (LightCycler 480 Multiwell Plates 96, white, -Roche-) in a total volume of $20 \mu \mathrm{L}$ containing $500 \mathrm{nM}$ of each primer, $100 \mathrm{nM}$ of each specific probe, $1 \times$ Light Cycler Probes Master (Roche) and $5 \mu \mathrm{L}$ of cDNA. The plates were sealing with an adhesive foil (Roche), and then the PCRs were run on a LightCycler 480 II System (Roche) using the following thermocycling conditions: an initial denaturation step $\left(95^{\circ} \mathrm{C}, 10 \mathrm{~min}\right.$ ) followed by 50 cycles of $95^{\circ} \mathrm{C}$ for $10 \mathrm{~s}$ (denaturation), $60^{\circ} \mathrm{C}$ for $30 \mathrm{~s}$ (annealing), and $72^{\circ} \mathrm{C}$ for $30 \mathrm{~s}$ (extension). qPCRs were run in triplicate for better accuracy and reproducibility. No template controls (NTC) from RT and qPCR were additionally included. Calibration curves for each chemokine, cytokine and reference gene were obtained using tenfold serial dilutions of a plasmid DNA containing the specific nucleotide sequence (PCR internal control) of each gene. The relative quantification of each gene was calculated automatically by LightCycler Relative Quantification Software, using the $\Delta \Delta$ CT-Method (Roche). The PCR efficiencies are shown in Table 1.

2.7. Statistical Analysis. NPAPTim, NPAPTit, and blank groups, whose pigs remained alive until the end of the experiment, were compared with each other. CHG group was not included in the comparative analysis because these animals died at a different time point. Descriptive statistics (mean, standard error), normality (Shapiro-Wilk), and 
TABLE 1: Oligonucleotides used in qPCR analysis.

\begin{tabular}{|c|c|c|c|c|c|}
\hline Genes & Sense & Sequences $\left(5^{\prime}\right.$ to $\left.3^{\prime}\right)$ & Product & Efficiency (\%) & Reference \\
\hline \multirow{3}{*}{ IL1- $\alpha$} & $\rightarrow$ & GTGCTCAAAACGAAGACGAACC & \multirow{3}{*}{$110 \mathrm{bp}$} & \multirow{3}{*}{$99.5 \pm 0.5$} & \multirow{3}{*}{ Duvigneau et al. [30] } \\
\hline & $\leftarrow$ & CATATTGCCATGCTTTTCCCAGAA & & & \\
\hline & $\rightarrow$ & FAM-TGCTGAAGGAGCTGCCTGAGACACCC-BHQ1 & & & \\
\hline \multirow{3}{*}{ IL1- $\beta$} & $\rightarrow$ & CCAAAGGCCGCCAAGATATAA & \multirow{3}{*}{75 bp } & \multirow{3}{*}{$100 \pm 0.2$} & \multirow{3}{*}{ Arce et al. [31] } \\
\hline & $\leftarrow$ & GGACCTCTGGGTATGGCTTTC & & & \\
\hline & $\rightarrow$ & FAM-CTGACTTCACCATGGAAGTCCTCTCTCCCTAAG-BHQ2 & & & \\
\hline \multirow{3}{*}{ TLR-4 } & $\rightarrow$ & GCCATCGCTGCTAACATCATC & \multirow{3}{*}{$108 \mathrm{bp}$} & \multirow{3}{*}{$99.7 \pm 0.2$} & \multirow{3}{*}{ This study } \\
\hline & $\leftarrow$ & CTCATACTCAAAGATACACCATCGG & & & \\
\hline & $\rightarrow$ & FAM-CAAAAGTCGGAAGGTTATTGTCGTGGTGTC-BHQ1 & & & \\
\hline \multirow{3}{*}{ IL-6 } & $\rightarrow$ & CTGGCAGAAAACAACCTGAACC & \multirow{3}{*}{$94 \mathrm{bp}$} & \multirow{3}{*}{$98.6 \pm 0.2$} & \multirow{3}{*}{ Duvigneau et al. [30] } \\
\hline & $\leftarrow$ & TGATTCTCATCAAGCAGGTCTCC & & & \\
\hline & $\rightarrow$ & FAM-TTGAACCCAGATTGGAAGCATCCGTCTTTT-BHQ1 & & & \\
\hline \multirow{3}{*}{ IL-10 } & $\rightarrow$ & CGGCGCTGTCATCAATTTCTG & \multirow{3}{*}{89 bp } & \multirow{3}{*}{$100.4 \pm 0.5$} & \multirow{3}{*}{ Duvigneau et al. [30] } \\
\hline & $\leftarrow$ & ССССTCTCTTGGAGCTTGCTA & & & \\
\hline & $\rightarrow$ & FAM-AGGCACTCTTCACCTCCTCCACGGC-BHQ1 & & & \\
\hline \multirow{3}{*}{ TNF- $\alpha$} & $\rightarrow$ & GCCCTGGTACGAACCCATCTA & \multirow{3}{*}{$91 \mathrm{bp}$} & \multirow{3}{*}{$99.1 \pm 0.3$} & \multirow{3}{*}{ Arce et al. [31] } \\
\hline & $\leftarrow$ & CAGATAGTCGGGCAGGTTGATCTC & & & \\
\hline & $\rightarrow$ & FAM-CCAGCTGGAGAAGGATGATCGACTCAGT-BHQ2 & & & \\
\hline \multirow{3}{*}{ CCL-2 } & $\rightarrow$ & ACCAGCAGCAAGTGTCCTAAAG & \multirow{3}{*}{92 bp } & \multirow{3}{*}{$99.4 \pm 0.7$} & \multirow{3}{*}{ Arce et al. [31] } \\
\hline & $\leftarrow$ & TCCTGGACCCACTTCTGCTT & & & \\
\hline & $\rightarrow$ & FAM-AGCAGTGATCTTCAAGACCATCGCGG-BHQ2 & & & \\
\hline \multirow{3}{*}{ CXCL-8 } & $\rightarrow$ & TTCGATGCCAGTGCATAAATA & & & \\
\hline & $\leftarrow$ & TGACAAGCTTAACAATGATTTCTGAA & $120 \mathrm{bp}$ & $99.8 \pm 0.8$ & Arce et al. [31] \\
\hline & $\rightarrow$ & FAM-CATТССАСАССТТТССАССССАААТТТАТС-BHQ2 & & & \\
\hline & $\rightarrow$ & ACATGGCCTCCAAGGAGTAAGA & & & \\
\hline GAPDH & $\leftarrow$ & GATCGAGTTGGGGCTGTGACT & $106 \mathrm{bp}$ & $99.2 \pm 0.6$ & Duvigneau et al. [30] \\
\hline & $\rightarrow$ & FAM-CCACCAACCCCAGCAAGAGCACGC-BHQ1 & & & \\
\hline & $\rightarrow$ & TGCTTTCACAGAATAATTCCAGGATTTA & & & \\
\hline cyclophilin & $\leftarrow$ & GACTTGCCACCAGTGCCATTA & 77 bp & $100.0 \pm 0.1$ & Duvigneau et al. [30] \\
\hline & $\rightarrow$ & FAM-TGCCAGGGTGGTGACTTCACACGCC-BHQ1 & & & \\
\hline & $\rightarrow$ & CTCGATCATGAAGTGCGACGT & & & \\
\hline$\beta$-actin & $\leftarrow$ & GTGATCTCCTTCTGCATCCTGTC & $114 \mathrm{bp}$ & $101.0 \pm 0.3$ & Duvigneau et al. [30] \\
\hline & $\rightarrow$ & FAM-ATCAGGAAGGACCTCTACGCCAACACGG-BHQ1 & & & \\
\hline
\end{tabular}

homoscedasticity (Bartlett's test) were determined. The analysis of cytokines expression levels was performed using oneway analysis of variance (ANOVA). Statistical means were contrasted by Tukey test $(P<0.05)$ using the Statistix 8.0 (Analytical Software, Roseville, MN, USA) [17]. The GraphPad Prism statistical program, version 5.0 (San Diego, CA, USA) was used for the figures.

\section{Results and Discussion}

3.1. Clinical Results. All pigs from the NPAPTim and NPAPTit groups survived until the end of experiment, and no clinical symptoms were observed. As could be expected, all pigs from CHG group died after the challenge, showing the clinical symptoms of Glässer's disease: high temperature, limb incoordination, swollen joints, severe dyspnea, and coughing. Clinical signs and histopathological findings have been extensively reported in Frandoloso et al. [15].

3.2. Evaluation of Endogenous Gene Expression. Three reference genes were tested due to different cell composition of the organs compared (brain, lungs, spleen, and lymph nodes). Cyclophilin showed constantly the highest homogeneous level of expression in all organs, with an average quantification cycle $(\mathrm{Cq})$ of $21.5 \pm 1.5$, whereas $\beta$-actin and GAPDH expression levels were lower and less constant in all tissues, with a $\mathrm{Cq}$ mean of $26.0 \pm 2.2$ and $27.0 \pm 3.3$, respectively. On the basis of these results, cyclophilin was used as reference gene for normalization of data. 
3.3. Chemokine Expression. No significant changes in transcript levels of CCL-2 (Figure 1(a)) and CXCL-8 (Figure 1(b)) genes were detected between NPAPTim, NPAPTit, and blank groups. There were only two exceptions: that of mediastinal and that of tracheobronchial nodes, for which the NPAPT groups showed a CCL-2 expression of about three- and seven-fold higher, respectively, than that of blank group $(P<0.05)$. However, $\mathrm{CHG}$ group transcribed high CCL-2 amounts in all tissues (Table 2). In lungs and draining lymph nodes, the CCL-2 transcription was approximately 20 and 50 times higher, respectively, than that of blank group. The origin of this chemokine could be justified by the activation of alveolar macrophages after $H$. parasuis contact or by the damage induced by this pathogen on epithelial cells. In the brain of CHG pigs, a high CCL-2 level was also observed (approximately 150 times higher than those of NPAPT and blank groups, Figure 1(a) and Table 2), which could be related to the presence of macrophages among the inflammatory cells seen in the histopathological study of this organ, whose lesions were compatible with meningitis [15]. Similarly, increased CCL-2 levels in the spleen and lymph nodes in $\mathrm{CHG}$ group seem to suggest a cellular proinflammatory immune response related to the activation of resident macrophages and dendritic cells, because the recruitment of inflammatory monocytes is dependent mainly on CCL-2 [18]. This overall increase in CCL-2 levels was coincident and could explain the elevation in the number of activated monocytes $\left(\mathrm{CD} 172 \alpha^{+} \mathrm{CD} 163^{+}\right)$in the peripheral blood [2].

CXCL-8 has been characterized as the main neutrophil activating chemoattractant chemokine [10]. The high CXCL-8 level measured in the brain of CHG pigs (about 50 times higher than that of blank group, Figure 1(b) and Table 2) could explain the great amount of neutrophils present in inflammatory infiltrates of this organ, as it has been already reported [19]. Bouchet et al. [19, 20] tested the in vitro ability of $H$. parasuis to induce IL-8 expression in porcine tracheal and brain vascular microendothelial cells and showed that both dead and alive $H$. parasuis were capable of producing high IL-8 levels. In our in vivo study, a correlation could be established between the severity of the suppurative meningitis [15] and the brain CXCL-8 expression. We also observed that the CXCL-8 expression after in vivo infection was very similar to that reported for the in vitro experiment by Bouchet et al. $[19,20]$. This result could indicate that the number of $H$. parasuis organisms reaching the brain was also similar to that used in in vitro infection, thus suggesting for the first time that $H$. parasuis could multiply and disseminate very fast in the natural host and that the in vitro model using brain and tracheal cells is adequate to perform studies about the expression of proinflammatory molecules. Identical with CCL- 2 expression, CXCL- 8 was also more transcribed in the tissues associated with the site of inoculation of $H$. parasuis (Table 2).

3.4. Cytokine Expression. IL- $1 \alpha$ levels were quite similar for all groups, except for CHG animals (Figure 1(c) and Table 2). However, the two vaccinated groups expressed significantly higher IL- $1 \beta$ levels than that of the blank group in lungs $(P<0.05$, Figure $1(\mathrm{~d}))$. A significantly higher rise in IL-1 $\beta$ expression was also observed in tracheobronchial nodes in NPAPTim group $(P<0.05)$. A previous study reported by our group [5] showed a high IL- $1 \alpha$ expression in the brain of a pig dying as a consequence of Glässer's disease. In the current report, we wanted to know how IL- $1 \beta$ responded to infection, and our results allowed us to assure that pigs suffering from Glässer's disease expressed high amounts of this cytokine. The greatest IL- $1 \beta$ expression in CHG group was measured in lungs, where the levels were about 50 and 25 times higher respectively than those of blank and NPAPT groups. A more marked difference was observed when comparing the IL-1 $\beta$ expression in the brain in CHG group (more than 500 times higher) with that measured in NPAPT groups (Figure $1(\mathrm{~d})$ and Table 2). IL-1 $\beta$ expression has been correlated with pathologies in which inflammatory manifestations are seen [21]. Our results suggest that IL- $\alpha$ and IL- $1 \beta$ could play an important role in the inflammatory response developed against $H$. parasuis, because both molecules can bind with the same signaling receptor and then induce the propagation of the inflammatory response [21].

The vaccinated groups showed an IL-6 concentration about five times higher in mediastinal nodes than that of blank group $(P<0.05$, Figure 1(e)). The highest IL- 6 expression in these three groups was detected in the secondary lymph tissues, being lower in lungs and especially in brain (Figure 1(e)). CHG group showed considerable IL-6 increases compared to the three other groups, between approximately six and 40 times higher depending on the tissue tested (Figure 1(e) and Table 2). IL-6 has been directly related to the synthesis of acute phase proteins and, in this respect, high levels of pig MAP, C-reactive protein and haptoglobin in the serum have been reported in pigs that died after experimental $H$. parasuis infection $[22,23]$. On the other hand, IL-6 plays an important role in Th2 lineage differentiation, being abundantly produced by antigen presenting cells [24]. The increase detected in mediastinal nodes in NPAPT groups could be associated to the stimulation and development of a Th2 response but not to a proinflammatory situation, mainly because low transcriptions of CXCL-8, IL-1 isoforms and TNF- $\alpha$ were observed in this tissue. Otherwise, the systemic transcription of high IL-6 levels measured in CHG group during $H$. parasuis pathogenesis could be due to the direct stimulation of this pathogen on mononuclear phagocytes, epithelial cells, and vascular endothelial cells [25].

Significantly lower values $(P<0.05)$ were detected in TNF- $\alpha$ expression in blank group in mandibular nodes when compared with any of the vaccinated groups (Figure 1(f)), while in the remaining tissues these levels remained similar. Moreover, the TNF- $\alpha$ levels increased markedly in $\mathrm{CHG}$ group (Table 2), especially in the secondary lymph tissues, where the expression was more than twelve times higher compared with any of the healthy groups (Figure $1(\mathrm{f})$ and Table 2). The TNF- $\alpha$ values observed in vaccinated and blank pigs suggest the existence of a basal expression level of this cytokine in swine, such as that observed in mice [26] and guinea pigs [27]. Biologically, the combination of TNF- $\alpha$ and IL-1 can induce changes in endothelial cells of 


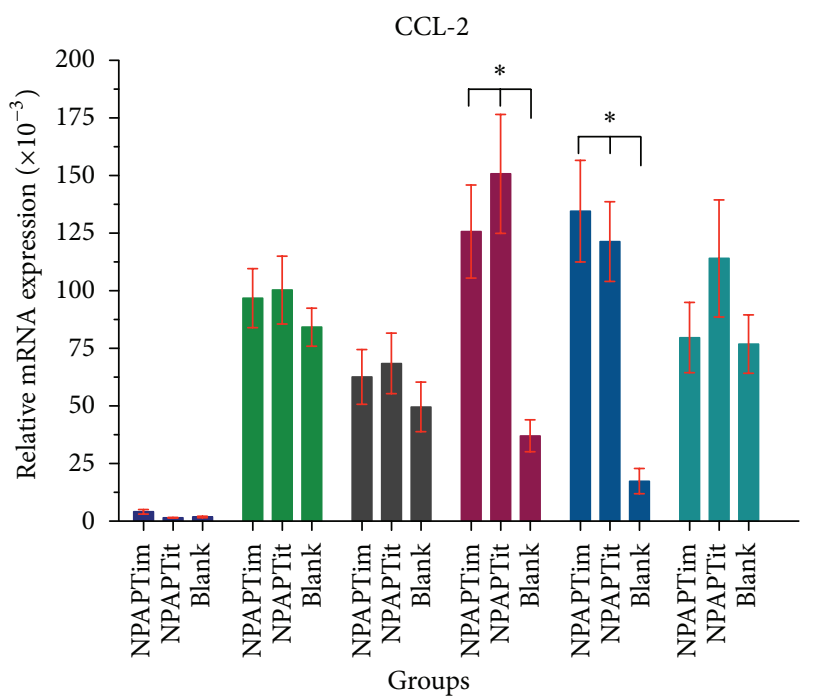

(a)

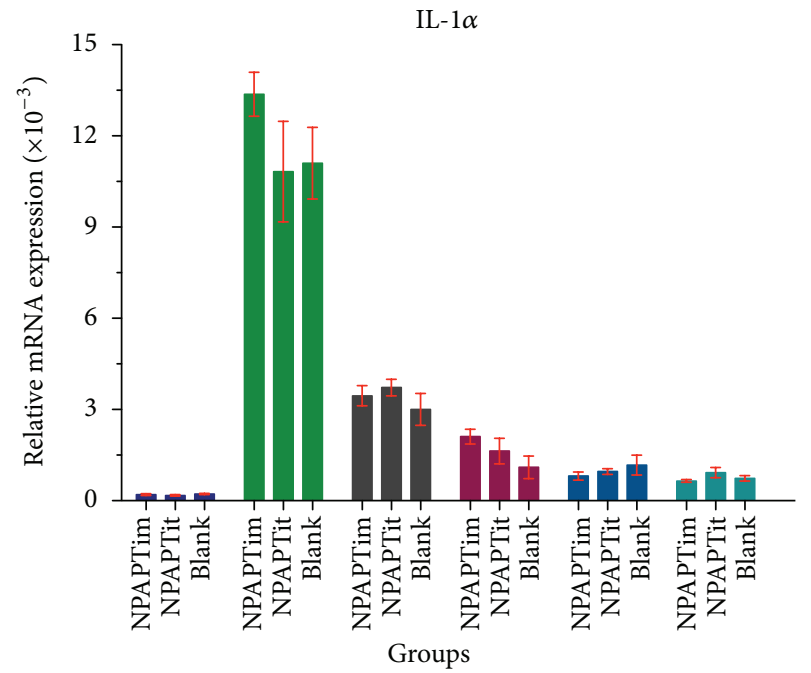

(c)

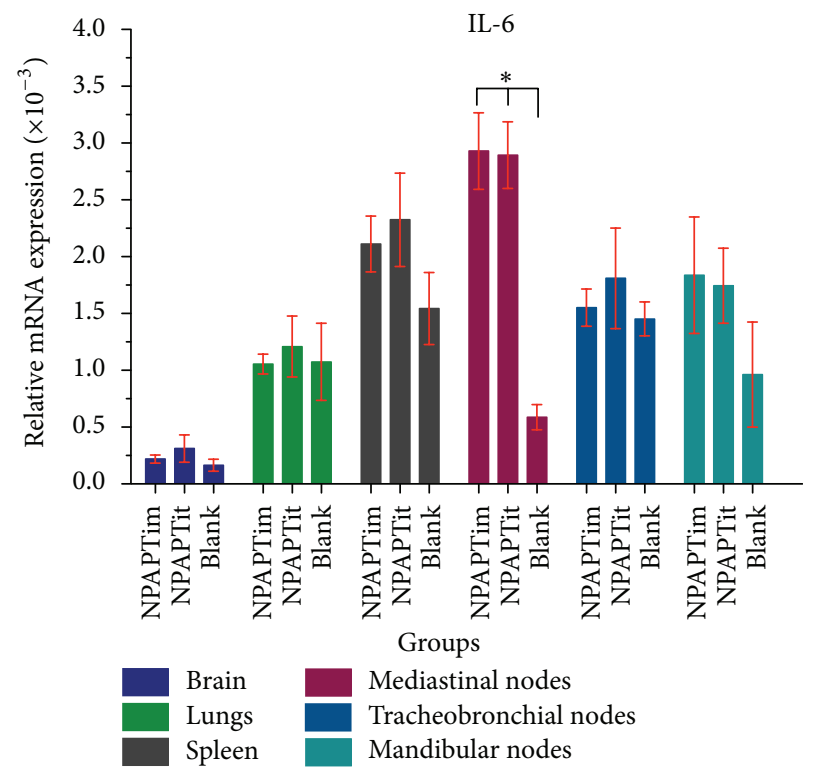

(e)

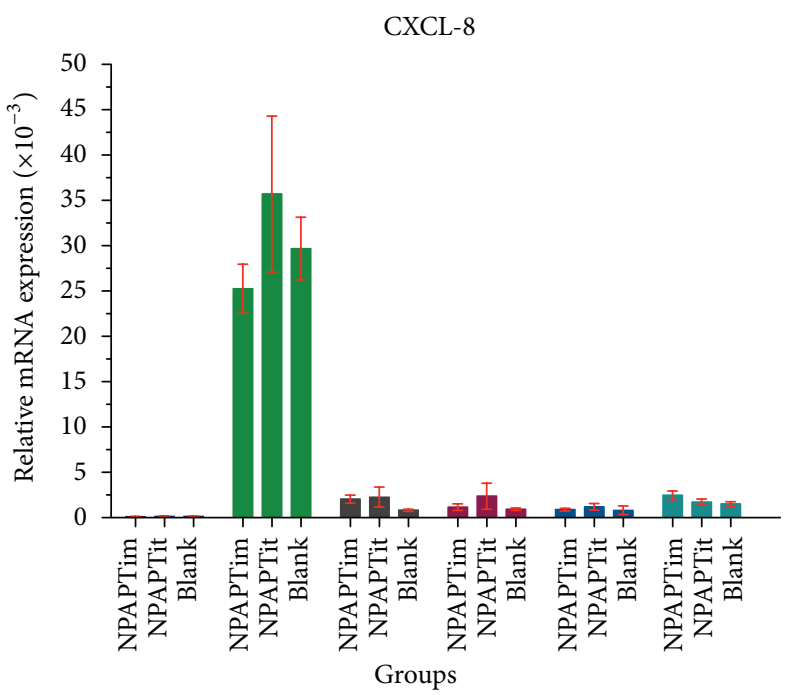

(b)

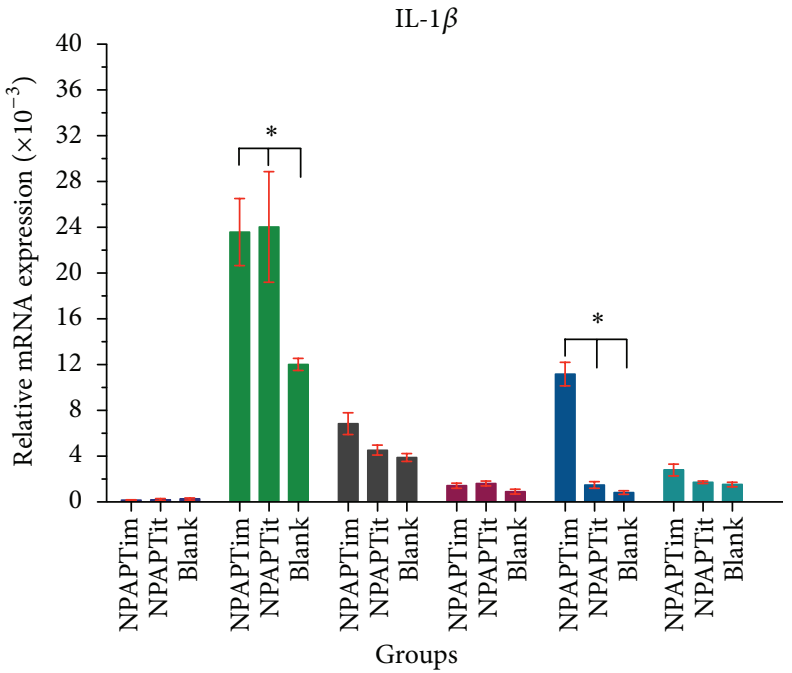

(d)

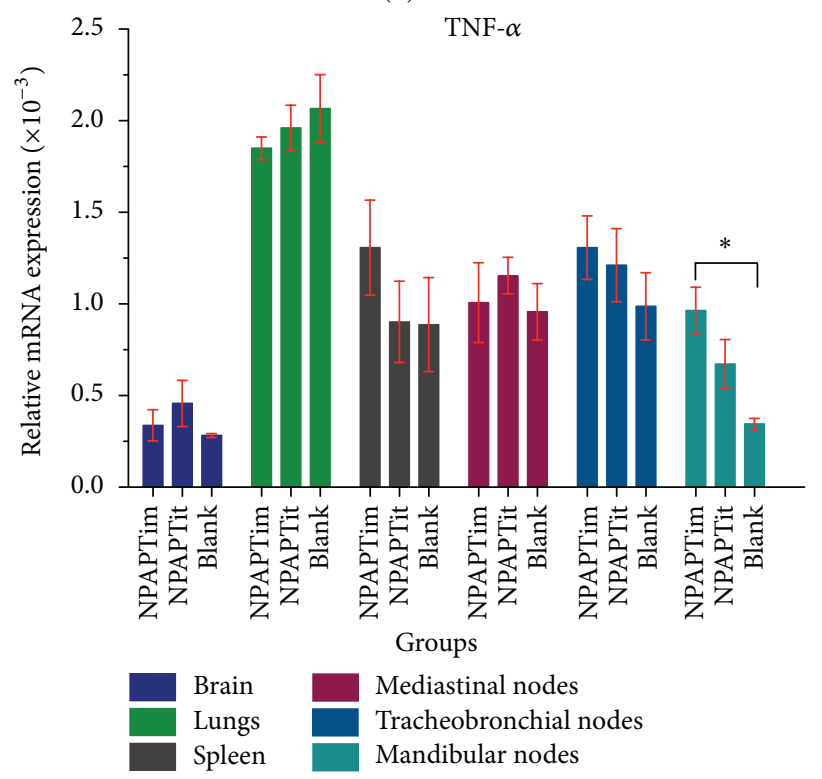

(f)

FIgUre 1: Continued. 


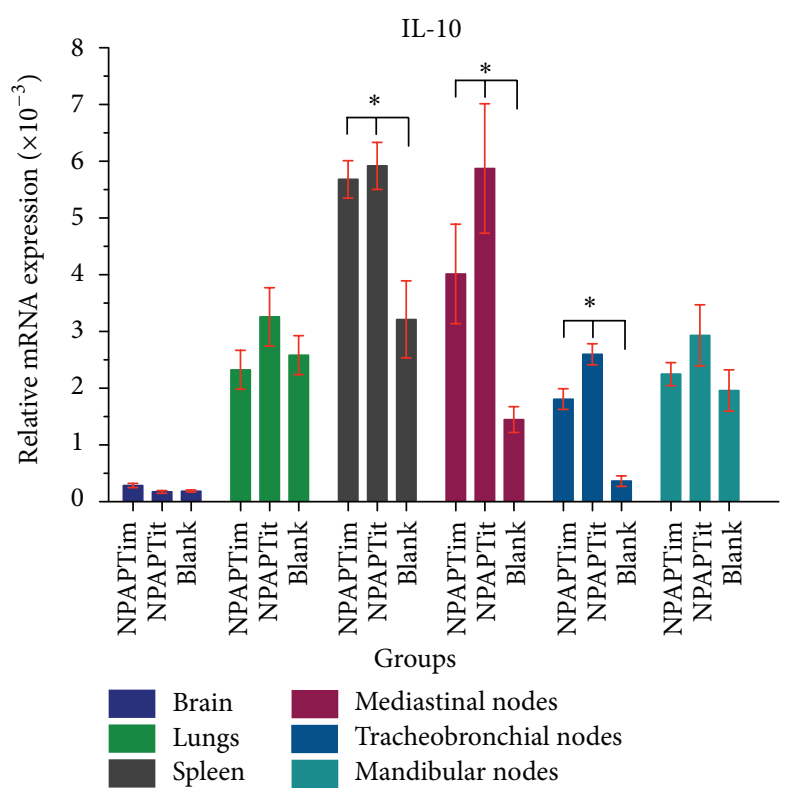

(g)

FIGURE 1: Relative mRNA expression rates of chemokines and cytokines from different tissues in NPAPTim, NPAPTit and blank groups. *indicates significant differences between groups $(P<0.05)$.

TABLE 2: Expression of proinflammatory molecules from different tissues in CHG group (mean \pm standard error).

\begin{tabular}{lcccccc}
\hline Molecules & & & & Tissue & & \\
& Brain & Lung & Spleen & Mediastinal nodes & Tracheobronchial nodes & Mandibular nodes \\
\hline CCL-2 & $204.2 \pm 40.2$ & $1673.2 \pm 96.5$ & $441.7 \pm 118.2$ & $901.5 \pm 58.9$ & $948.8 \pm 73.8$ & $257.1 \pm 45.2$ \\
CXCL-8 & $55 \pm 3.6$ & $887.6 \pm 34.2$ & $12.7 \pm 1.6$ & $431.5 \pm 74.3$ & $470.7 \pm 104.4$ & $17.3 \pm 2.4$ \\
IL-1 $\alpha$ & $57.7 \pm 5.8$ & $365.4 \pm 45.6$ & $35.3 \pm 1.7$ & $142.1 \pm 20.7$ & $15.3 \pm 3.2$ & $15.5 \pm 2.1$ \\
IL-1 $\beta$ & $141.5 \pm 11.4$ & $615.4 \pm 76.1$ & $92.7 \pm 2.8$ & $184.1 \pm 32.2$ & $119.2 \pm 13.1$ & $63 \pm 12.2$ \\
IL-6 & $2.5 \pm 0.4$ & $37.4 \pm 5.9$ & $20.8 \pm 3.7$ & $35.8 \pm 1.8$ & $115.1 \pm 20.42$ & $13.6 \pm 0.7$ \\
TNF- $\alpha$ & $10.5 \pm 0.7$ & $10.9 \pm 1.1$ & $19 \pm 3.2$ & $75.1 \pm 5.4$ & $22.2 \pm 4.3$ & $16.5 \pm 0.6$ \\
IL-10 & $17.5 \pm 1.7$ & $48.1 \pm 6.6$ & $10.8 \pm 1.8$ & $6.4 \pm 1.7$ & $7.1 \pm 0.8$ & $12.1 \pm 1.5$ \\
\hline
\end{tabular}

${ }^{*}$ Relative mRNA expression $\left(\times 10^{-3}\right)$.

small vessels, thus increasing the adherence of inflammatory cells. In addition, a TNF- $\alpha$ increase could cause edema and vascular thrombosis [28]. These findings allow us to relate the high expression of IL-1 isoforms, and TNF- $\alpha$ with the edema, lung congestion and vascular thrombosis observed microscopically in a previous report in CHG pigs [15].

The two vaccinated groups showed transcription levels statistically higher than the blank group for IL-10 in spleen and mediastinal and tracheobronchial nodes $(P<0.05$, Figure $1(\mathrm{~g})$ ). However, these values were at least thrice lower than those measured for CHG group, except for mediastinal nodes (Table 2). Taking into account the regulative effect exerted by IL-10 on the different cells belonging to innate and adaptive systems, it could be suggested that the elevation observed in CHG group would be a regulative action of the secretion of proinflammatory cytokines. On the other hand, Go et al. [29] showed that B cells cultivated in vitro and stimulated with IL-10 increased the class II MHC expression on the surface of B cells. The increase of IL-10 expression in spleen in NPAPT pigs could be explained by this fact, mainly because these animals showed hyperplasia in the white pulp, characterized by an increase of the spleen germinal centers and by a peripheral increase in B cells, and in the expression of SLAIIDR molecules [2].

\section{Conclusion}

The experimental infection of colostrum-deprived pigs with $H$. parasuis Nagasaki strain induced an overregulation of the expression of proinflammatory chemokines and cytokines related to innate immunity. Because of the differences in the expression between the protected (NPAPTim and NPAPTit) and nonprotected (CHG) groups, CCL-2, CXCL-8, IL- $1 \alpha$, IL-1 $\beta$, and IL- 6 may be considered the best inflammatory markers to $H$. parasuis infection in target organs. Finally, the protection conferred by NPAPT vaccines was enough to prevent an inflammatory reaction mediated by CCL-2, CXCL-8, IL-1 $\alpha$, IL-1 $\beta$, IL-6, TNF- $\alpha$, and IL-10, making NPAPT antigen 
a suitable candidate to control Glässer's disease caused by $H$. parasuis Nagasaki strain.

\section{Conflict of Interests}

The authors declare that they have no conflict of interests with Cycler Probes Master (Roche) and Analytical Software (Roseville, MN, USA).

\section{Acknowledgments}

Research in the laboratory of R. Frandoloso and S. MartínezMartínez was supported by long-predoctoral fellowships from the Spanish Ministry of Science and Innovation, as well as by Grant AGL-2011-23195 (Spanish Ministry of "Economy and Competitivity"). The authors also acknowledge Estela Costa for the language editing of their paper.

\section{References}

[1] R. Medzhitov and C. Janeway Jr., "Innate immune recognition: mechanisms and pathways," Immunological Reviews, vol. 173, pp. 89-97, 2000.

[2] R. Frandoloso, S. Martínez-Martínez, S. Yubero, E. F. Rodríguez-Ferri, and C. B. Gutiérrez Martín, "New insights in cellular immune response in colostrum-deprived pigs after immunization with subunit and commercial vaccines against Glässer's disease," Cell Immunology, vol. 277, pp. 74-82, 2012.

[3] M. J. Baarsch, R. W. Scamurra, K. Burger, D. L. Foss, S. K. Maheswaran, and M. P. Murtaugh, "Inflammatory cytokine expression in swine experimentally infected with Actinobacillus pleuropneumoniae," Infection and Immunity, vol. 63, no. 9, pp. 3587-3594, 1995.

[4] C. Choi, D. Kwon, K. Jung et al., "Expression of inflammatory cytokines in pigs experimentally infected with Mycoplasma hyopneumoniae," Journal of Comparative Pathology, vol. 134, no. 1, pp. 44-50, 2006.

[5] A. J. Martín de la Fuente, E. F. Rodríguez Ferri, F. Tejerina, R. Frandoloso, S. Martínez, and C. B. Gutiérrez Martín, "Cytokine expression in colostrum-deprived pigs immunized and challenged with Haemophilus parasuis," Research in Veterinary Science, vol. 87, pp. 47-52, 2009.

[6] D. K. Dalton, S. Pitts-Meek, S. Keshav, I. S. Figari, A. Bradley, and T. A. Stewart, "Multiple defects of immune cell function in mice with disrupted interferon- $\gamma$ genes," Science, vol. 259, no. 5102, pp. 1739-1742, 1993.

[7] B. Zhao, S. A. Stavchansky, R. A. Bowden, and P. D. Bowman, "Effect of interleukin- $1 \beta$ and tumor necrosis factor- $\alpha$ on gene expression in human endothelial cells," The American Journal of Physiology, vol. 284, no. 6, pp. C1577-C1583, 2003.

[8] S. Safaya, M. H. Steinberg, and E. S. Klings, "Monocytes from sickle cell disease patients induce differential pulmonary endothelial gene expression via activation of NF- $\kappa \mathrm{B}$ signaling pathway," Molecular Immunology, vol. 50, no. 1-2, pp. 117-123, 2012.

[9] T. Kishimoto, “The biology of interleukin-6," Blood, vol. 74, no. 1, pp. 1-10, 1989.

[10] J. Catusse, P. Faye, B. Loillier et al., "Cloning and characterization of guinea pig interleukin-8 receptor," Biochemical Pharmacology, vol. 66, no. 7, pp. 1171-1180, 2003.
[11] B. Beutler, "Sepsis begins at the interface of pathogen and host," Biochemical Society Transactions, vol. 29, no. 6, pp. 853-859, 2001.

[12] R. de Waal Malefyt, J. Abrams, B. Bennett, C. G. Figdor, and J. E. de Vries, "Interleukin 10(IL-10) inhibits cytokine synthesis by human monocytes: an autoregulatory role of IL-10 produced by monocytes," Journal of Experimental Medicine, vol. 174, no. 5, pp. 1209-1220, 1991.

[13] D. F. Fiorentino, A. Zlotnik, T. R. Mosmann, M. Howard, and A. O'Garra, "IL-10 inhibits cytokine production by activated macrophages," Journal of Immunology, vol. 147, no. 11, pp. 38153822, 1991.

[14] I. Blanco, L. Galina-Pantoja, S. Oliveira, C. Pijoan, C. Sánchez, and A. Canals, "Comparison between Haemophilus parasuis infection in colostrums-deprived and sow-reared piglets," Veterinary Microbiology, vol. 103, no. 1-2, pp. 21-27, 2004.

[15] R. Frandoloso, S. Martínez, E. F. Rodríguez-Ferri et al., "Development and characterization of protective Haemophilus parasuis subunit vaccines based on native proteins with affinity to porcine transferrin and comparison with other subunit and commercial vaccines," Clinical and Vaccine Immunology, vol. 18, pp. 50-58, 2011.

[16] S. A. Bustin, V. Benes, J. A. Garson et al., “The MIQE guidelines: minimum information for publication of quantitative real-time PCR experiments," Clinical Chemistry, vol. 55, no. 4, pp. 611-622, 2009.

[17] Statistix 8. 0: User's Manual, Analytical software, Tallahasse, Fla, USA, 2003.

[18] R. E. Gerszten, E. A. Garcia-Zepeda, Y.-C. Lim et al., "MCP1 and IL-8 trigger firm adhesion of monocytes to vascular endothelium under flow conditions," Nature, vol. 398, no. 6729, pp. 718-725, 1999.

[19] B. Bouchet, G. Vanier, M. Jacques, and M. Gottschalk, "Interactions of Haemophilus parasuis and its LOS with porcine brain microvascular endothelial cells," Veterinary Research, vol. 39, no. 5, pp. 42-47, 2008.

[20] B. Bouchet, G. Vanier, M. Jacques, E. Auger, and M. Gottschalk, "Studies on the interactions of Haemophilus parasuis with porcine epithelial tracheal cells: limited role of LOS in apoptosis and pro-inflammatory cytokine release," Microbial Pathogenesis, vol. 46, no. 2, pp. 108-113, 2009.

[21] P. Rider, Y. Carmi, O. Guttman et al., "IL-1 $\alpha$ and IL-1 $\beta$ recruit different myeloid cells and promote different stages of sterile inflammation," Journal of Immunology, vol. 187, no. 9, pp. 48354843, 2011.

[22] A. J. Martín de la Fuente, R. Carpintero, E. F. Rodríguez Ferri, M. A. Álava, F. Lampreave, and C. B. Gutiérrez Martín, "Acutephase protein response in pigs experimentally infected with Haemophilus parasuis," Comparative Immunology Microbiology and Infectious Diseases, vol. 33, pp. 455-465, 2010.

[23] S. Martínez Martínez, R. Frandoloso, C. B. Gutiérrez Martín et al., "Acute phase protein concentrations in colostrum-deprived pigs immunized with subunit and commercial vaccines against Glässer's disease," Veterinary Immunology and Immunopathology, vol. 144, pp. 61-67, 2011.

[24] R. V. Luckheeram, R. Zhou, A. D. Verma, and B. Xia, "CD4+T cells: differentiation and functions," Clinical and Developmental Immunology, vol. 2012, Article ID 925135, 12 pages, 2012.

[25] E. Bartoccioni, F. Scuderi, M. Marino, and C. Provenzano, "IL-6, monocyte infiltration and parenchymal cells," Trends in immunology, vol. 24, no. 6, pp. 299-300, 2003. 
[26] M. Michishita, Y. Yoshida, H. Uchino, and K. Nagata, "Induction of tumor necrosis factor- $\alpha$ and its receptors during differentiation in myeloid leukemic cells along the monocytic pathway: a possible regulatory mechanism for TNF- $\alpha$ production," Journal of Biological Chemistry, vol. 265, no. 15, pp. 8751-8759, 1990.

[27] H. Cho and D. N. McMurray, "Neutralization of tumor necrosis factor alpha suppresses antigen-specific type 1 cytokine responses and reverses the inhibition of mycobacterial survival in cocultures of immune guinea pig T lymphocytes and infected macrophages," Infection and Immunity, vol. 73, no. 12, pp. 84378441, 2005.

[28] A. Cerami, "Inflamatory cytokines," Clinical Immunology and Immunopathology, vol. 62, pp. S3-S10, 1992.

[29] N. F. Go, B. E. Castle, R. Barrett et al., "Interleukin 10, a novel $\mathrm{B}$ cell stimulatory factor: unresponsiveness of X chromosomelinked immunodeficiency B cells," Journal of Experimental Medicine, vol. 172, no. 6, pp. 1625-1631, 1990.

[30] J. C. Duvigneau, R. T. Hartl, S. Groiss, and M. Gemeiner, "Quantitative simultaneous multiplex real-time PCR for the detection of porcine cytokines," Journal of Immunological Methods, vol. 306, no. 1-2, pp. 16-27, 2005.

[31] C. Arce, M. Ramírez-Boo, C. Lucena, and J. J. Garrido, "Innate immune activation of swine intestinal epithelial cell lines (IPEC-J2 and IPI-2I) in response to LPS from Salmonella typhimurium," Comparative Immunology, Microbiology and Infectious Diseases, vol. 33, no. 2, pp. 161-174, 2010. 


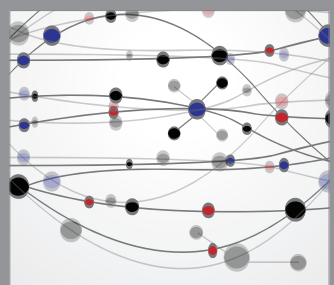

The Scientific World Journal
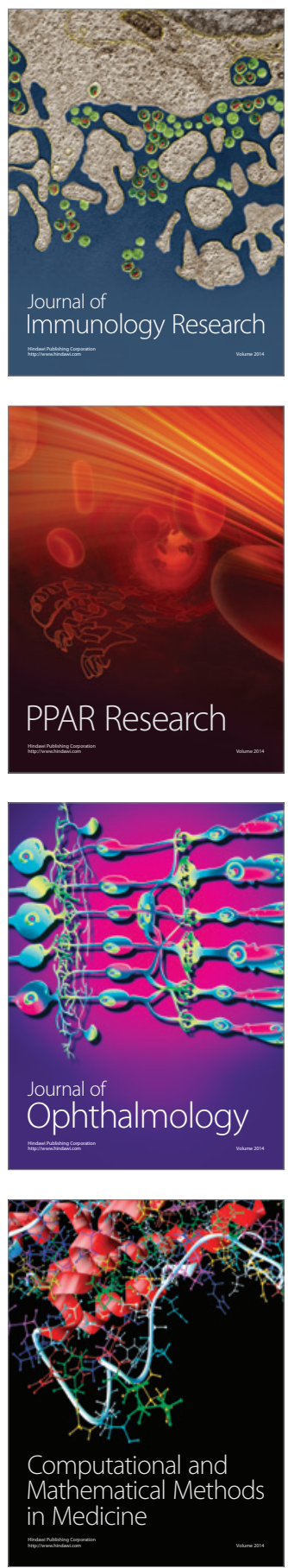

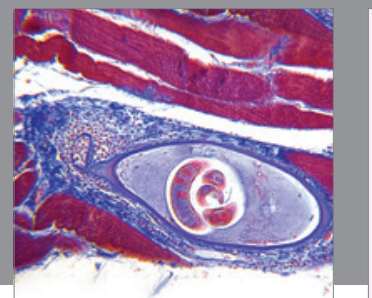

Gastroenterology

Research and Practice
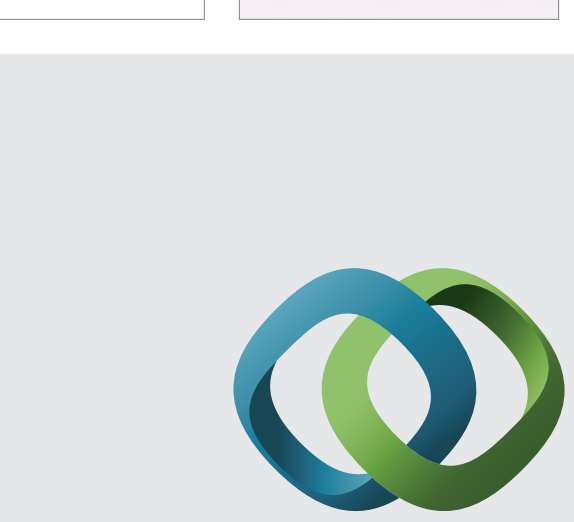

\section{Hindawi}

Submit your manuscripts at

http://www.hindawi.com
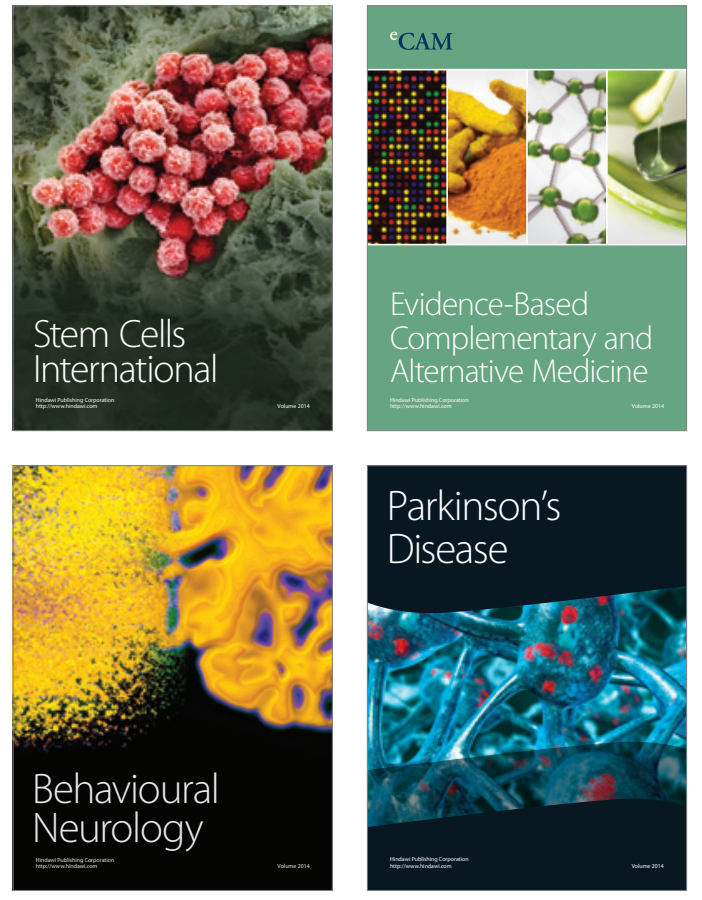
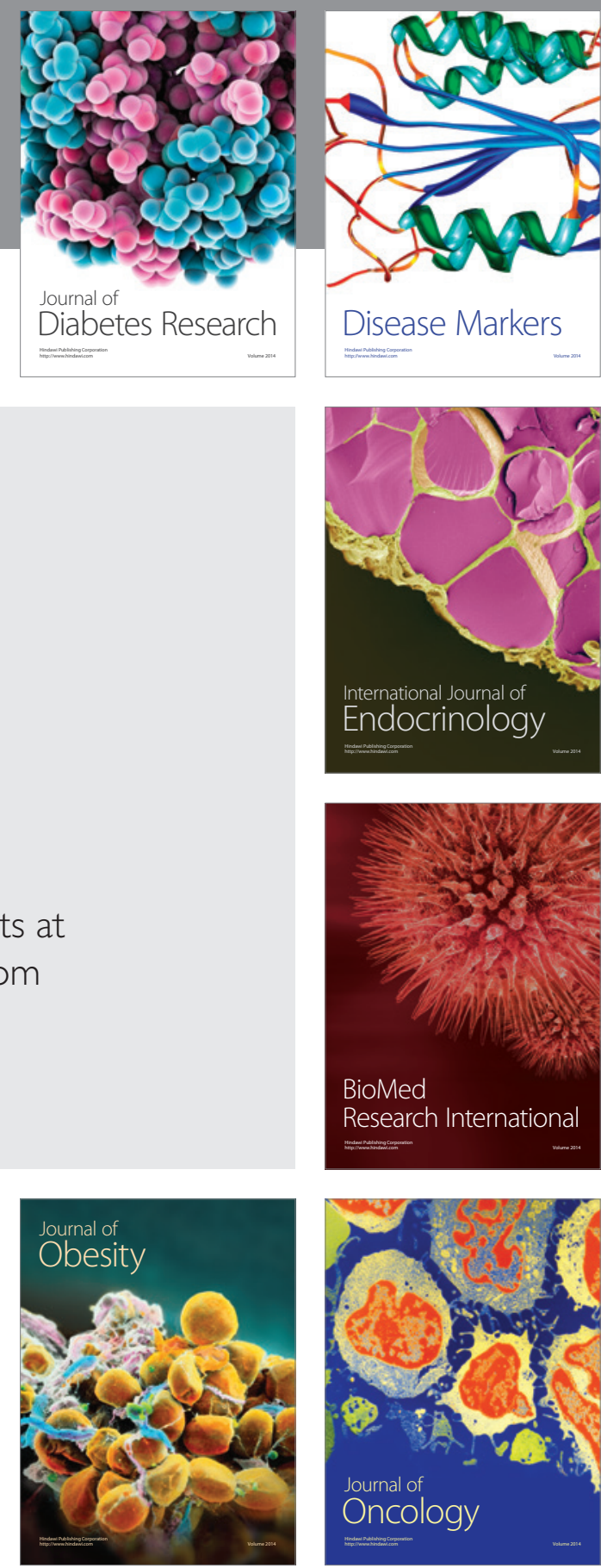

Disease Markers
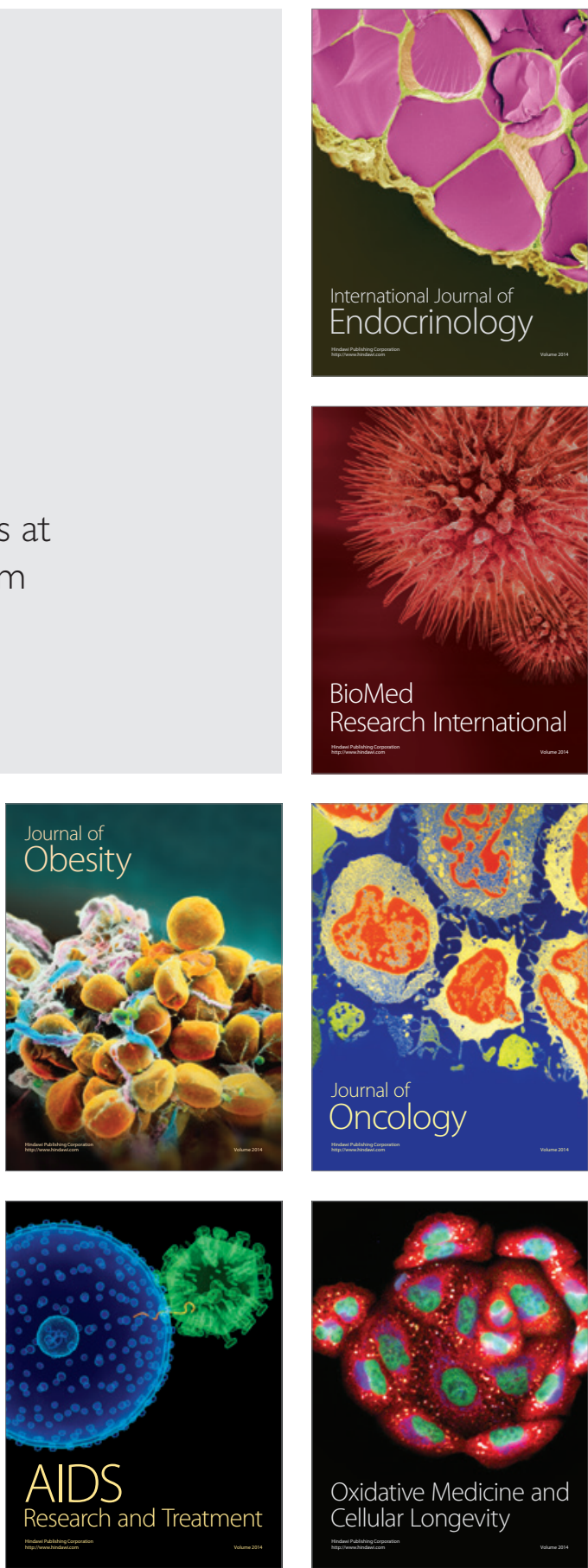